\title{
Porphyromonas Gingivalis May Seek the Alzheimer's Disease Brain to Acquire Iron from Its Surplus
}

\author{
Ingar Olsen* \\ Department of Oral Biology, Faculty of Dentistry, University of Oslo, Oslo, Norway
}

Accepted 23 December 2020

Pre-press 12 January 2021

\begin{abstract}
Iron accumulates in the brain of subjects with Alzheimer's disease (AD). Here it promotes the aggregation of amyloid- $\beta$ plaques in which it is abundant. Iron induces amyloid- $\beta$ neurotoxicity by damaging free radicals and causing oxidative stress in brain areas with neurodegeneration. It can also bind to tau in $\mathrm{AD}$ and enhance the toxicity of tau through co-localization with neurofibrillary tangles and induce accumulation of these tangles. Porphyromonas gingivalis is a key oral pathogen in the widespread biofilm-induced disease "chronic" periodontitis, and recently, has been suggested to have an important role in the pathogenesis of AD. P. gingivalis has an obligate requirement for iron. The current paper suggests that $P$. gingivalis seeks the $\mathrm{AD}$ brain, where it has been identified, to satisfy this need. If this is correct, iron chelators binding iron could have beneficial effects in the treatment of AD. Indeed, studies from both animal AD models and humans with AD have indicated that iron chelators, e.g., lactoferrin, can have such effects. Lactoferrin can also inhibit $P$. gingivalis growth and proteinases and its ability to form biofilm.
\end{abstract}

Keywords: Biofilm, brain, immunity, iron dysregulation, iron requirement, senescence

\section{INTRODUCTION}

Iron can be found in the human brain where its levels increase with age $[1,2]$. Importantly, iron accelerates the aggregation of the amyloid- $\beta(\mathrm{A} \beta)$ peptide [3-6] and is abundant in $A \beta$ plaques [7]. This may enhance the risk of Alzheimer's disease (AD) where $\mathrm{A} \beta$ plaques are one of the hallmarks [8]. Ayton et al. [9] were the first to demonstrate a relationship between iron and $A \beta$ deposition in a longitudinal clinical study on AD. According to Chung et al. [10], iron, after binding to $A \beta$, regulates $A \beta$ toxicity in the central nervous system (CNS). Iron induces $A \beta$

${ }^{*}$ Correspondence to: Ingar Olsen, Department of Oral Biology, Faculty of Dentistry, University of Oslo, P.O. Box 1052, Blindern, 0316 Oslo, Norway. Tel.: +47 90777482; E-mail: ingar. olsen@odont.uio.no. neurotoxicity by producing free radical damage and oxidative stress in brain areas with neurodegeneration, probably by promoting aggregation of $\mathrm{A} \beta[11$, 12]. Accordingly, iron can induce $A \beta$ aggregation and has been found to be directly associated with $\mathrm{A} \beta$ plaque in vitro and in vivo [8].

In biology, iron cycles between ferrous $\left(\mathrm{Fe}^{2+}\right)$ and ferric $\left(\mathrm{Fe}^{3+}\right)$ states. This chemistry is used by cells for many redox reactions but can cause deleterious oxidative stress which contributes to AD [8]. Specifically, $\mathrm{Fe}^{3+}$ accumulates in $\mathrm{A} \beta$ plaques and neurofibrillary tangles (NFTs) of AD brains and is the more potent of the two ions in neurotoxicity [2]. Everett et al. [13] found $A \beta$ capable of accumulating $\mathrm{Fe}^{3+}$ within their aggregates, which resulted in $\mathrm{A} \beta$-mediated reduction of $\mathrm{Fe}^{3+}$ to a redox-active iron $\left({ }^{2+}\right)$ phase. According to these authors, the ability of 
iron to form redox-active phases from ferric precursors provides an origin both for the redox-active iron seen in AD tissue and the increased levels of oxidative stress characteristic of AD.

Additionally, ferritin, which is the major iron-binding protein of brain cells [11], is associated with deposition of amyloid. Increased neuronal iron even increases the synthesis and processing of the amyloid- $\beta$ protein precursor to produce $A \beta[12,14,15]$. Increased brain iron is associated with plaque-iron loading and microglial iron inclusions [16]. Stimulation of cultured microglia with interferon $\gamma$ and $\mathrm{A} \beta$ made iron accumulate in these cells [17]. The microglia became glycolytic and iron-retentive, and their phagocytic and chemotactic function was reduced. In microglia of mice, iron accumulation triggered a cascade of events that caused altered metabolism and compromised function [17]. Dysregulation of iron homeostasis causing accumulation in neurons can promote changes in $A \beta$ and tau (the second hallmark of AD). According to Gibbons et al. [18], unique misfolded conformations of tau, referred to as strains, have been hypothesized to underlie the distinct neuroanatomical and cellular distribution of pathological tau aggregates. These authors detected a specific tau strain in $\mathrm{AD}$ by using immunohistochemistry with novel conformation-selective tau antibodies that distinguished it from non-AD tauopathies. $A \beta$ and tau can also disrupt iron homeostasis [2]. This suggests a positive-feedback pathogenic process in AD.

It has been suggested that iron can bind to tau protein(s) in $\mathrm{AD}$ and affect their toxicity through co-localization with NFTs $[19,20]$. Like A $\beta$ plaques, iron can induce accumulation of abnormally phosphorylated tau [20, 21]. Iron increases hyperphosphorylation of tau by stimulating cyclin kinase 5 (CDK5) and glycogen synthase kinase (GSK-3 $\beta$ ) activity and reduces the activity of phosphatase $1 \mathrm{~A}$ [8]. The latter is the major tau phosphatase in host cells $[22,23]$.

\section{DYSREGULATED IRON HOMEOSTASIS AND ALZHEIMER'S DISEASE}

$\mathrm{AD}$ is the most common form of neurodegenerative diseases. As mentioned, the two neuropathological hallmarks in $\mathrm{AD}$ are extracellular aggregations of $\mathrm{A} \beta$ peptide and cytoplasmic inclusions within neurons called NFTs. The latter are microtubule-associated proteins composed of filaments of hyperphosphory- lated tau. Both types of hallmark proteins are probably acting synergistically in the pathogenesis of $\mathrm{AD}$ (for a review, see [2]).

A causative interplay between dysregulation of iron homeostasis and amyloid plaque formation has been suggested [16]. The authors hypothesized that iron dysregulation and $A \beta$ plaque pathology act synergistically in the process of neurodegeneration and can start a downward cascade of events ending up with manifestation of AD. In an APP(swe)/PS1(del taE9) transgenic mouse model of $\mathrm{AD}$, light microscopy revealed that onset of plaque formation occurred at 8 months' age. Detectable traces of free iron, but no ferritin, were seen around plaques at this age, while their accumulation in and around $A \beta$ plaques had increased at 13 months. Ferritin accumulated mainly at the edge of $A \beta$ plaques, while a smaller amount of free iron was observed in the plaque-free tissue, as well as in and around A $\beta$ plaques [24]. Secreted ferritin, which reflects the intracellular iron load, was increased in the cerebrospinal fluid of individuals with mild cognitive impairment and may be used to predict a near-term progression risk of the disease [2]. Accordingly, free iron and ferritin accumulation seem to follow the formation of amyloid plaques. Another study showed that iron homeostasis is changed in $\mathrm{AD}$ patients with lower iron in their serum and an iron overload in several specific brain regions [25].

Iron can induce abnormalities in signal transduction processes related to oxidative damage [26]. Dysregulation of the brain iron homeostasis results in the production of reactive oxygen species, generating reactive aldehydes, which, together with further oxidative insults, cause oxidative modification of proteins, manifested by carbonyl formation [27]. These misfolded and damaged proteins overwhelm the ubiquitin/proteasome system, leading to accumulation of the characteristic inclusion bodies seen in many neurodegenerative diseases [27].

$\mathrm{AD}$ is characterized by dementia resulting from selective loss of neurons in the hippocampus and cortex [2]. Hare et al. [28] reported increased intrusion of iron into the gray matter of the AD brain compared to controls. This indicated either loss of iron homeostasis in this vulnerable brain region or increased inflammatory processes as a response to chronic neurodegeneration. The authors also observed a trend to increased iron within the white matter of the frontal cortex, potentially due to disrupted iron metabolism preceding loss of myelin integrity.

Accordingly, an imbalance in brain iron has been established in AD. This imbalance can even affect 
expression of and response to inflammatory agents [29] like microorganisms. Deregulation of iron homeostasis also causes generation of reactive oxygen species that can underlie an increased oxidative stress burden [15] or lead to oxidative damage [19]. Similar to accumulation of iron, oxidative stress is an early event in the pathogenesis of AD.

The source of the excess iron in the AD brain is unclear. However, over the last years, neuroimaging studies have increasingly implicated micro- and macro-structural abnormalities in the white matter in the risk and progression of $\mathrm{AD}$, suggesting that in addition to the neuronal pathology characteristic of the disease, white matter degeneration and demyelination can be important pathophysiological characteristics. One theory involves oligodendrocytes which have the highest iron content of all cell types. Their iron content increases with age and even further in $\mathrm{AD}$ [30]. The high iron content and a low antioxidant content make oligodendrocytes most vulnerable to oxidative stress in the CNS. If oxidative stress is increased by age, or $\mathrm{AD}$, it may lead to increased cell damage [31, 32].

Another possible source of excess brain iron is the black pigment within the outer membrane of $P$. gingivalis which carries bound $[\mathrm{Fe}(\mathrm{III}) \mathrm{PPIX}]_{2} \mathrm{O}$ on its surface [33]. On invasion into the CNS by $P$. gingivalis these Fe-containing compounds will follow and exert toxicity towards the host's brain cells. The cell surface muco-oxy dimer layer formed may also serve as a protective barrier against reactive oxidants and permit $P$. gingivalis to maintain a local anaerobic environment.

\section{IRON AND SENESCENCE}

AD is prevalent in elderly people due to the biological aging process. Iron dysmetabolism is closely connected to cellular senescence and loss of aerobic glycolysis (for a review, see [34]). Iron induces DNA damage and endothelial cell senescence that increase the permeability of the blood-brain barrier and the risk of microbial translocation to the brain [34-36]. Moreover, iron activates NLRP3 inflammasomes, linking this biometal to AD inflammation [37], dysfunctional mitochondria, and impaired mitophagy [38-40]. The level of the iron storage protein, ferritin, is thought to be a reliable senescence marker, yielding support to the concept of ferrosenescence [41]. This has given credit to a new, unproved hypothesis, suggesting that age-related increase in the free iron pool resuscitates dormant microbes in the brain parenchyma [42].

\section{PORPHYROMONAS GINGIVALIS AND ALZHEIMER'S DISEASE}

Recent research has opened the possibility that $\mathrm{AD}$ can be caused by infection and neuroinflammation accompanying the former. A field receiving increasing attention recently has been "chronic" periodontitis which is a common oral disease in the adult population all over the world. Periodontal pathogens and their main virulence factors like lipopolysaccharide (LPS) and gingipains have been detected in the brain of AD patients and animal models of AD [43-48]. Dominy et al. [44] found P. gingivalis DNA and gingipain antigens in human $\mathrm{AD}$ brains and showed in mice that oral administration of small-molecule gingipain inhibitors blocked gingipain-induced neurodegeneration. The findings in the human brains appeared even before AD manifested and progressed further and could therefore not be a result of inadequate oral hygiene accompanying AD. P. gingivalis could also be detected in the cerebrospinal fluid of $\mathrm{AD}$ patients confirming that the CNS had been affected. These authors [44] also found that RgpB localized with neurons, astrocytes, and pathology in the hippocampus, and Kgp in the cerebral cortex of $\mathrm{AD}$ patients. So far, this is the strongest indication that AD can be associated with "chronic" periodontitis where $P$. gingivalis is a keystone bacterium [49-51].

\section{PORPHYROMONAS GINGIVALIS AND IMMUNITY}

Virtually all human pathogens have an absolute requirement for iron. An important task of innate immunity is to limit iron availability to invading microorganisms (nutritional immunity). To be successful in causing disease, human pathogens must have mechanisms to circumvent nutritional immunity [52]. An important pathogen in the oral microbiota is $P$. gingivalis which in addition to being a keystone pathogen in periodontitis [49-51], has recently been associated with AD [43, 44, 53-56]. This bacterium is a master of immune subversion [57, 58], probably also in AD [59]. Central in this task is its strategy to overcome iron-withholding defenses. Of note is also that immunity can be declined in AD due immunosenescence [60]. 


\section{PORPHYROMONAS GINGIVALIS AND ITS REQUIREMENTS FOR IRON}

$P$. gingivalis, which is a heme-dependent bacterium, lacks siderophores. Instead, it uses specific outer membrane receptors, proteases (particularly gingipains), and lipoproteins to acquire iron/heme from the environment $[61,62] . P$. gingivalis can even use heme acquisition systems of accompanying bacteria to satisfy its own requirements [63].

Specific proteins are operating in $P$. gingivalis for iron/heme capture [60] and specific genes for iron/heme utilization [64]. Outer membrane vesicles, containing gingipains, are crucial for both micro- and macro-nutrient capture of iron for $P$. gingivalis, especially of heme [65].

$P$. gingivalis has an enzyme system which opens the heme ring for iron release. Thus, Daspher et al. [66] characterized a novel outer membrane heminbinding protein in $P$. gingivalis: IhtB (iron heme transport, formerly designated Pga30). The authors found this protein, released from the cell surface, to bind hemin by using hemin-agarose. Analysis of the

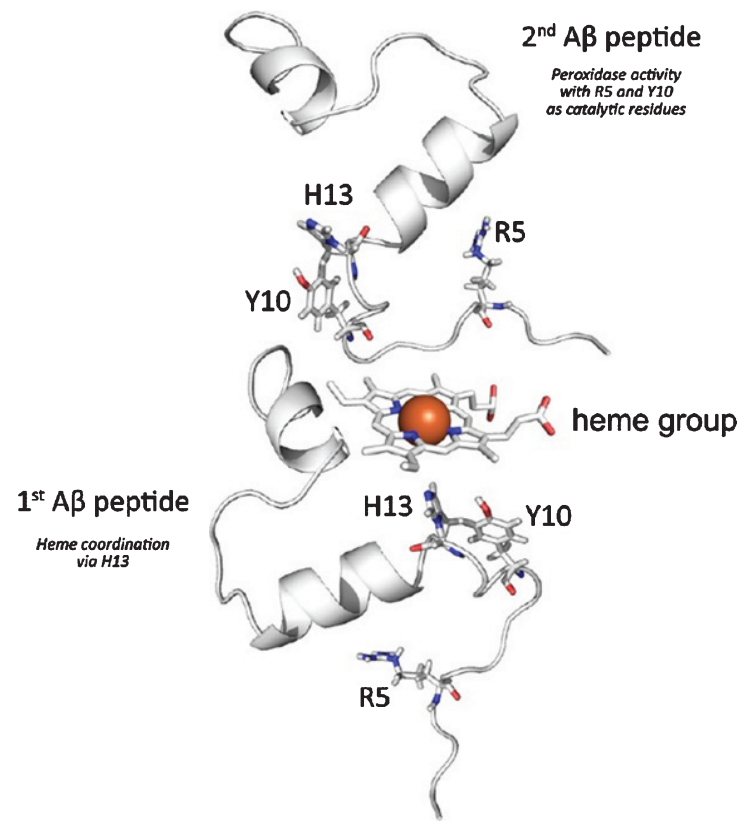

Fig. 1. Schematic presentation of amyloid $\beta$ (A $\beta$ )-heme complex formation based on published investigations on the complexation of free heme by $A \beta$. Interaction is proposed to mainly take place between heme and the $\mathrm{N}$-terminal part of the peptide. While one peptide is mainly involved in the coordination of the heme iron at the distal heme site via $\mathrm{H} 13$, a second peptide may coordinate at the proximal heme site to provide R5 and Y10, which are responsible for the subsequent peroxidase activity of the complex. Collected from [72]. deduced amino acid sequence of IhtB showed significant similarity to the Salmonella typhimurium protein CbiK which is a cobalt chelatase structurally related to the ATP-dependent family of ferrochelatases. The authors suggested that IhtB is a peripheral outer membrane chelatase that could remove iron from heme prior to uptake by $P$. gingivalis. This hypothesis needs confirmation. Since it is not clear if iron removed by IhtB actually is taken up by the cell, this could potentially add to the free iron pool of the AD brain. $P$. gingivalis probably expresses other proteinaceous binding sites which are important in the binding/transport of heme/hemin from the host, for example A-LPS [67]. Others have assumed that uptake of heme in $P$. gingivalis may require binding of heme to Kgp and thereafter binding of Kgp to the heme/hemoglobin receptor HmuR [68].

Goulet et al. [69] reported that $P$. gingivalis gingipains also degrade human transferrin, providing sources of iron and transferrin peptides. The ironcontaining fragments or the release of iron itself was suggested to contribute to tissue destruction by catalyzing the formation of toxic $\mathrm{HO}^{*}$.

$P$. gingivalis also uses hemoglobin as an iron source. Notably, this source is used much more effectively than other iron-containing compounds under an iron-limited environment [70].

\section{PORPHYROMONAS GINGIVALIS MAY SEEK THE BRAIN TO ACQUIRE HEME}

Heme is necessary for $P$. gingivalis to survive in its site of origin (the periodontal pocket) and probably also in its peripheral site (the AD brain). The main sources of heme for $P$. gingivalis in the mouth are hemoproteins in the saliva and gingival crevicular fluid and erythrocytes. In the AD brain, heme is probably bound to $A \beta$ in a complex. Recently, it was found that the formation and enzymatic activity of $A \beta$-heme complexes are pathological key features of $\mathrm{AD}[71,72]$ (Fig. 1). Accordingly, free heme and amyloid- $\beta$ could be a dangerous liaison in AD.

By lysing $\mathrm{A} \beta$ plaques, which in $\mathrm{AD}$ are overloaded with iron, $P$. gingivalis probably achieves access to iron either as heme, free iron or ferritin (one of the intracellular iron-storage proteins of $P$. gingivalis). Ferritin accumulates mainly at the edge of $A \beta$ plaques, while a smaller amount of free iron is observed in the plaque-free tissue, as well as in and around A $\beta$ plaques [24]. Whether $P$. gingivalis (1) lyses plaques through their gingipains, (2) acquires 
iron in the plaque surroundings, (3) extracts iron from plaque-free brain tissue, or (4) takes it from ferritin or microglia, the consequences of acquisition of iron from these sources may aggravate the iron dyshomeostasis existing in the AD brain. Aberrations in the brain iron homeostasis can increase the levels of this redox-active metal, causing dislocalization of the metal and catastrophic oxidative damage to sensitive cellular and subcellular structures [73]. Iron levels are lower in serum of $\mathrm{AD}$ patients than in $A \beta$ plaques [25]. $A \beta$ plaques may therefore be a preferred peripheral site of $P$. gingivalis for iron supplementation rather than serum.

\section{CONCLUDING REMARKS}

It seems plausible that one reason for $P$. gingivalis seeking the brain and establishing itself here is its requirements for iron. This could occur in the brains of healthy old people or at the mild cognitive impairment stage, or later in the AD process. As suggested previously, a 10-year lag phase of "chronic" periodontitis is needed for this widespread oral disease to become a risk factor for AD [55]. However, $P$. gingivalis may possibly also contribute to the free iron pool in the AD brain through its bound $[\mathrm{Fe}(\mathrm{III}) \mathrm{PPIX}]_{2} \mathrm{O}$ and IhtB. Presence of $P$. gingivalis in the brain could tip the delicate iron balance here causing iron dyshomeostasis and also promote development of AD through its shed inflammagens such as LPS and proteolytic enzymes transferred through the blood brain barrier by its outer membrane vesicles [74]. This imbalance may affect expression of and response to inflammatory agents [29] such as brain-residing microorganisms. Age-related increase

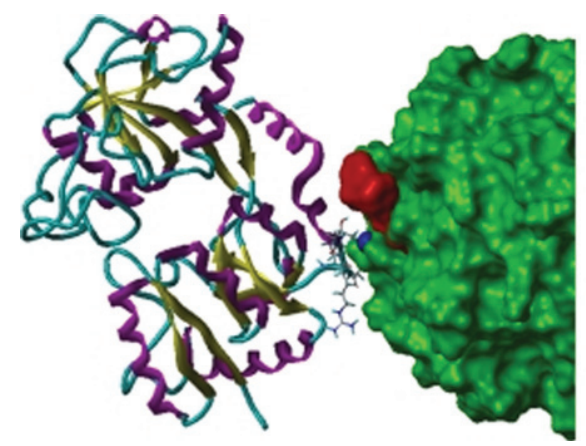

in the free iron pool may also resuscitate dormant microbes in the brain parenchyma which could be another important feature of AD [42]. The growth of these organisms in vivo is limited by a lack of free iron, and iron dysregulation could be an important factor in their resuscitation [75-77]. Iron dysregulation and microbial aberrations could also affect the hematological system by promoting fibrin amyloidogenesis and pathological clotting, paving the way for iron-induced clotting in the development of $\mathrm{AD}$ [78].

As a consequence of the high levels of iron in $\mathrm{AD}$, iron chelators have been tested in the treatment of $\mathrm{AD}$ in rodents and man $[15,79,80]$. Iron chelators caused reduction in $\mathrm{Fe}^{3+}$-induced $\mathrm{A} \beta_{42}$ accumulation in vitro [81], in tau aggregates from $\mathrm{AD}$ patients, and in slices of human AD brains [82, 83]. In genetic mouse models of $\mathrm{AD}$, iron chelators reduced cognitive impairment together with GSK3 $\beta$ activity, tau phosphorylation, $\mathrm{A} \beta$ generation and accumulation of $A \beta$ in the hippocampus. Iron chelators in $A D$ treatment of other rodent models have also provided encouraging results (reviewed by D'Mello and Kindy [2]). Even oxidative stress and activation of microglia have been diminished by iron chelators. Of particular note, sustained administration of iron chelators to patients with early $\mathrm{AD}$ slowed the progression of dementia [84].

Molecules of special interest as iron chelators are lactoferrin (LF) and ergothioneine (for reviews, see $[85,86])$. These nutraceuticals can act as ironmopping agents. LF has been found important in the treatment of $\mathrm{AD}$ where it may prevent iron deposition and block $A \beta$-aggregation, tauopathy and neuronal damage [87]. LF can also inhibit $P$. gingivalis growth and proteinases (Fig. 2) and its ability to form biofilm $[88,89]$.

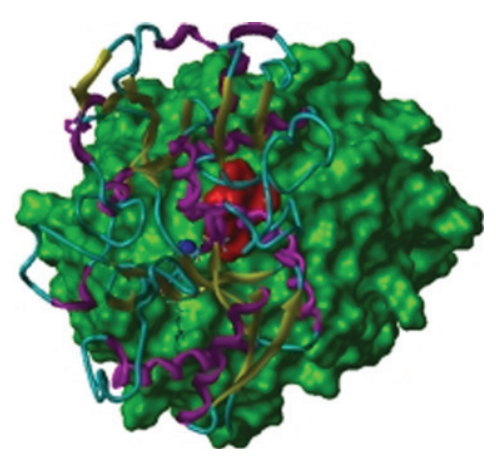

Fig. 2. Orthographic view of the modeled lactoferrin (LF)-RgpB complex. The solvent-accessible surface of RgpB is green, the dark blue space-filling atom is the zink ion bound to the catalytic histidine $\left(\mathrm{His}^{244}\right)$ of $\mathrm{RgpB}$. LF is illustrated as a ribbon structure $(\beta$-strand in yellow, $\alpha$-helix in magenta, and coil in cyan). The side-chains of residues that moved to within $3 \AA$ of RgpB during the dynamics simulation are shown as "capped sticks". The location of the atoms of the RgpB inhibitor, DFFR-chloromethylketone, is shown by red-space filling atoms (from: [89] Permission granted by RightsLink/ASM) 
Iron in the brain seems to be an underappreciated driver of $\mathrm{AD}$ disease progression. Its cooperation with bacteria, in this case $P$. gingivalis, could increase the toxic potential of both in the $\mathrm{AD}$ pathogenesis. It seems plausible that iron chelators by binding iron in the AD brain may lessen the signs of AD and simultaneously make the brain less favorable for survival of $P$. gingivalis and other putative AD pathogens. This hypothesis, previously overlooked, should be confirmed before firm conclusions can be made.

\section{CONFLICT OF INTEREST}

The author has no conflict of interest to report.

\section{REFERENCES}

[1] Aquino D, Bizzi A, Grisoli M, Garavaglia B, Bruzzone MG, Nardocci N, Savoiardo M, Chiapparini L (2009) Age-related iron deposition in the basal ganglia: Quantitative analysis in healthy subjects. Radiology 252, 165-172.

[2] D'Mello SR, Kindy MC (2020) Overdosing on iron: Elevated iron and degenerative brain disorders. Exp Biol Med (Maywood) 245, 1444-1473.

[3] Mantyh PW, Ghilardi JR, Rogers S, DeMaster E, Allen CJ, Stimson ER, Maggio JE (1993) Aluminum, iron, and zinc ions promote aggregation of physiological concentrations of $\beta$-amyloid peptide. J Neurochem 61, 1171-1174.

[4] Huang X, Atwood CS, Moir RD, Hartshorn MA, Tanzi RE, Bush AI (2004) Trace metal contamination initiates the apparent auto-aggregation, amyloidosis, and oligomerization of Alzheimer's A $\beta$ peptides. J Biol Inorg Chem $\mathbf{9}$, 954-960.

[5] Liu B, Moloney A, Meehan S, Morris K, Thomas SE, Serpell LC, Hider R, Marciniak SJ, Lomas DA, Crowther DC (2011) Iron promotes the toxicity of amyloid $\beta$ peptide by impeding its ordered aggregation. J Biol Chem 286, 4248-4256.

[6] Ott S, Dziadulewicz N, Crowther DC (2015) Iron is a specific cofactor for distinct oxidation- and aggregationdependent A $\beta$ toxicity mechanisms in a Drosophila model. Dis Model Mech 8, 657-671.

[7] Meadowcroft MD, Peters DG, Dewal RP, Connor JR, Qing $X$, Yang QX (2014) The effect of iron in MRI and transverse relaxation of amyloid- $\beta$ plaques in Alzheimer's disease. NMR Biomed 28, 297-305.

[8] Nikseresht S, Bush AI, Ayton S (2019) Treating Alzheimer's disease by targeting iron. Br J Pharmacol 176, 3622-3635.

[9] Ayton S, Diouf I, Bush AI (2018) Evidence that iron accelerates Alzheimer's pathology: A CSF biomarker study. $J$ Neurol Neurosurg Psychiatry 89, 456-460.

[10] Chung JY, Kim HS, Song J (2018) Iron metabolism in diabetes-induced Alzheimer's disease: A focus on insulin resistance in the brain. Biometals 31, 705-714.

[11] Kwiatek-Majkusiak J, Dickson DW, Tacik P, Aoki N, Tomasiuk R, Koziorowski D, Friedman A (2015) Relationships between typical histopathological hallmarks and the ferritin in the hippocampus from patients with Alzheimer's disease. Acta Neurobiol Exp (Wars) 75, 391-398.
[12] Amit T, Bar-Am O, Mechlovich D, Kupershmidt L, Youdim MBH, Weinreb O (2017) The novel multitarget iron chelating and propargylamine drug M30 affects APP regulation and processing activities in Alzheimer's disease models. Neuropharmacology 123, 359-367.

[13] Everett J, Céspedes E, Shelford LR, Exley C, Collingwood JF, Dobson J, van der Laan G, Jenkins CA, Arenholz E, Telling ND (2014) Ferrous iron formation following the co-aggregation of ferric iron and the Alzheimer's disease peptide $\beta$-amyloid (1-42). J R Soc Interface 11, 20140165.

[14] Li X, Liu Y, Zheng Q, Yao G, Cheng P, Bu G, Xu H, Zhang YW (2013) Ferritin light chain interacts with PEN-2 and affects $\gamma$-secretase activity. Neurosci Lett 548, 90-94.

[15] Greenough MA, Camakaris J, Bush AI (2013) Metal dyshomeostasis and oxidative stress in Alzheimer's disease. Neurochem Int 62, 540-555.

[16] Peters DG, Pollack AN, Cheng KC, Sun D, Saido T, Haaf MP, Yang QX, Connor JR, Meadowcroft MD (2018) Dietary lipophilic iron alters amyloidogenesis and microglial morphology in Alzheimer's disease knock-in APP mice. Metallomics 10, 426-443.

[17] McIntosh A, Mela V, Harty C, Minogue AM, Costello DA, Kerskens C, Lynch MA (2019) Iron accumulation in microglia triggers a cascade of events that leads to altered metabolism and compromised function in APP/PS1 mice. Brain Pathol 29, 606-621.

[18] Gibbons GS, Banks RA, Kim B, Changolkar L, Riddie DM, Leight SN, Irwin DJ, Trojanowski JQ, Lee VMY (2018) Detection of Alzheimer disease (AD)-specific tau pathology in $\mathrm{AD}$ and nonAD tauopathies by immunohistochemistry with novel conformation-selective tau antibodies. $\mathrm{J} \mathrm{Neu}$ ropathol Exp Neurol 77, 216-228.

[19] Tofaris GK, Revesz T, Jacques TS, Papacostas S, Chataway J (2007) Adult-onset neurodegeneration with brain iron accumulation and cortical $\alpha$-synuclein and tau pathology: A distinct clinicopathological entity. Arch Neurol 6, 280-282.

[20] Rao SS, Adlard PA (2018) Untangling tau and iron: Exploring the interaction between iron and tau in neurodegeneration. Front Mol Neurosci 11, 276.

[21] Sayre LM, Perry G, Harris PL, Liu Y, Schubert KA, Smith MA (2000) In situ oxidative catalysis by neurofibrillary tangles and senile plaques in Alzheimer's disease: A central role for bound transition metals. J Neurochem 74, 270-279.

[22] Xie L, Zheng W, Xin N, Xie J-W, Wang T, Wang Z-Y (2012) Ebselen inhibits iron-induced tau phosphorylation by attenuating DMT1 up-regulation and cellular iron uptake. Neurochem Int 61, 334-340.

[23] Jung KJ, Kim DH, Lee EK, Song CW, Yu BP, Chung HY (2013) Oxidative stress induces inactivation of protein phosphatase $2 \mathrm{~A}$, promoting proinflammatory NF- $\kappa \mathrm{B}$ in aged rat kidney. Free Radic Biol Med 61, 206-217.

[24] Svobodová H, Kosnáč D, Balázsiová Z, Tanila H, Miettinen PO, Sierra A, Vitovič P, Wagner A, Polák Š, Kopáni M (2019) Elevated age-related cortical iron, ferritin and amyloid plaques in APP(swe)/PS1(deltaE9) transgenic mouse model of Alzheimer's disease. Physiol Res 68 (Suppl 4), S445-S451.

[25] Tao Y, Wang Y, Rogers JT, Wang F (2014) Perturbed iron distribution in Alzheimer's disease serum, cerebrospinal fluid, and selected brain regions: A systematic review and meta-analysis. J Alzheimers Dis 42, 679-690.

[26] Ong WY, Farooqui AA (2005) Iron, neuroinflammation, and Alzheimer's disease. J Alzheimers Dis 8, 183-200; discussion 209-215. 
[27] Crichton RR, Dexter DT, Ward RJ (2011) Brain iron metabolism and its perturbation in neurological diseases. J Neural Transm (Vienna) 118, 301-314.

[28] Hare DJ, Raven EP, Roberts BR, Bogeski M, Portbury SD, McLean CA, Masters CL, Connor JR, Bush AI, Crouch PJ, Doble PA (2016) Laser ablation-inductively coupled plasma-mass spectrometry imaging of white and gray matter iron distribution in Alzheimer's disease frontal cortex. Neuroimage 137, 124-131.

[29] Connor JR, Lee SY (2006) HFE mutations and Alzheimer's disease. J Alzheimers Dis 10, 267-276.

[30] Bartzokis G (2011) Alzheimer's disease as homeostatic responses to age-related myelin breakdown. Neurobiol Aging 32, 1341-1371.

[31] Tse KH, Herrup K (2017) DNA damage in the oligodendrocyte lineage and its role in brain aging. Mech Ageing Dev 161, 37-50.

[32] Nasrabady SE, Rizvi B, Goldman JE, Brickman AM (2018) White matter changes in Alzheimer's disease: A focus on myelin and oligodendrocytes. Acta Neuropathol Commun 6, 22.

[33] Smalley JW, Birss AJ, Silver J (1998) The periodontal pathogen Porphyromonas gingivalis harnesses the chemistry of the mu-oxo bishaem of iron protoporphyrin IX to protect against hydrogen peroxide. FEMS Microbiol Lett 183, 159-164.

[34] Osorio C, Kanukuntla T, Diaz E, Jafri N, Cummings M, Sfera A (2019) The post-amyloid era in Alzheimer's disease: Trust your gut feeling. Front Aging Neurosci 11, 143.

[35] Won SM, Lee JH, Park UJ, Gwag J, Gwag BJ, Lee YB (2011) Iron mediates endothelial cell damage and bloodbrain barrier opening in the hippocampus after transient forebrain ischemia in rats. Exp Mol Med 43, 121-128.

[36] Mollet IG, Patel D, Govani FS, Giess A, Paschalaki K, Periyasamy M, Lidington EC, Mason JC, Jones MD, Game L, Ali S, Shovlin CL (2016) Low dose iron treatments induce a DNA damage response in human endothelial cells within minutes. PLoS One 11, e0147990.

[37] Olsen I, Singhrao SK (2016) Inflammasome involvement in Alzheimer's disease. J Alzheimers Dis 54, 45-53.

[38] Allen GFG, Toth R, James J, Ganley IG (2013) Loss of iron triggers PINK1/Parkin-independent mitophagy. EMBO Rep 14, 1127-1135.

[39] Nakamura K, Kawakami T, Yamamoto N, Tomizawa M, Fujiwara T, Ishii T, Harigae H, Ogasawara K (2016) Activation of the NLRP3 inflammasome by cellular labile iron. Exp Hematol 44, 116-124.

[40] Sfera A, Gradini R, Cummings M, Diaz E, Price AI, Osorio C (2018) Rusty microglia: Trainers of innate immunity in Alzheimer's disease. Front Neurol 9, 1062.

[41] Masaldan S, Clatworthy SAS, Gamell C, Meggyesy PM, Rigopoulos AT, Haupt S, Haupt Y, Denoyer D, Adlard PA, Bush AI, Cater MA (2018) Iron accumulation in senescent cells is coupled with impaired ferritinophagy and inhibition of ferroptosis. Redox Biol 14, 100-115.

[42] Pretorius E, Bester J, Page MJ, Kell DB (2018) The potential of LPS-binding protein to reverse amyloid formation in plasma fibrin of individuals with Alzheimer-type dementia. Front Aging Neurosci 10, 257.

[43] Ilievski V, Zuchowska PK, Green SJ, Toth PT, Ragozzino ME, Le K, Aljewari HW, O’Brien-Simpson NM, Reynolds EC, Watanabe K (2018) Chronic oral application of a periodontal pathogen results in brain inflammation, neurodegeneration and amyloid beta production in wild type mice. PLoS One 13, e0204941.
[44] Dominy SS, Lynch C, Ermini F, Benedyk M, Marczyk A, Konradi A, Nguyen M, Haditsch U, Raha D, Griffin C, Holsinger LJ, Arastu-Kapur S, Kaba S, Lee A, Ryder MI, Potempa B, Mydel P, Hellvard A, Adamowicz K, Hasturk H, Walker GD, Reynolds EC, Faull RLM, Curtis MA, Dragunow M, Potempa J (2019) Porphyromonas gingivalis in Alzheimer's disease brains: Evidence for disease causation and treatment with small-molecule inhibitors. $S c i A d v \mathbf{5}$, eaau3333.

[45] Poole S, Singhrao SK, Kesavalu L, Curtis MA, Crean SJ (2013) Determining the presence of periodontopathic virulence factors in short-term postmortem Alzheimer's disease brain tissue. J Alzheimers Dis 36, 665-677.

[46] Poole S, Singhrao SK, Chukkapalli S, Rivera M, Velsko I, Kesavalu L (2015) Active invasion of Porphyromonas gingivalis and infection-induced complement activation in $\mathrm{ApoE}^{-/-}$mice brains. J Alzheimers Dis 43, 67-80.

[47] Nie R, Wu Z, Ni J, Zeng F, Yu W, Zhang Y, Kadowaki T, Kashiwazaki H, Teeling JL, Zhou Y (2019) Porphyromonas gingivalis infection induces amyloid- $\beta$ accumulation in monocytes/macrophages. J Alzheimers Dis 72, 479-494.

[48] Siddiqui H, Eribe ERK, Singhrao SK, Olsen I (2019) High throughput sequencing detects gingivitis and periodontal oral bacteria in Alzheimer's disease autopsy brains. Neuro Res 1,3 .

[49] Socransky SS, Haffajee AD, Cugini MA, Smith C, Kent RL Jr (1998) Microbial complexes in subgingival plaque. J Clin Periodontol 25, 134-144.

[50] Hajishengallis G, Darveau RP, Curtis MA (2012) The keystone-pathogen hypothesis. Nat Rev Microbiol 10, 717725.

[51] Darveau RP, Hajishengallis G, Curtis MA (2012) Porphyromonas gingivalis as a potential community activist. J Dent Res 91, 816-820.

[52] Cassat JE, Skaar EP (2013) Iron in infection and immunity. Cell Host Microbe 13, 509-519.

[53] Olsen I, Singhrao SK (2019) Is there a link between genetic defects in the complement cascade and Porphyromonas gingivalis in Alzheimer's disease? J Oral Microbiol 12, 167648.

[54] Olsen I, Singhrao SK (2019) Poor oral health and its neurological consequences: Mechanisms of Porphyromonas gingivalis involvement in cognitive dysfunction. Curr Oral Health Rep 6, 120-129.

[55] Singhrao SK, Olsen I (2019) Assessing the role of Porphyromonas gingivalis in periodontitis to determine a causative relationship with Alzheimer's disease. J Oral Microbiol 11, 1563405.

[56] Olsen I, Singhrao SK (2020) Interaction between genetic factors, Porphyromonas gingivalis and microglia to promote Alzheimer's disease. J Oral Microbiol 12, 1820834.

[57] Hajishengallis G, Harokopakis E (2007) Porphyromonas gingivalis interactions with complement receptor 3 (CR3): Innate immunity or immune evasion? Front Biosci 12, 45474557.

[58] Hajishengallis G (2011) Immune evasion strategies of Porphyromonas gingivalis. J Oral Biosc 53, 233-240.

[59] Olsen I, Taubman MA, Singhrao SK (2016) Porphyromonas gingivalis suppresses adaptive immunity in periodontitis, atherosclerosis, and Alzheimer's disease. J Oral Microbiol 8, 33029 .

[60] Castelo-Branco C, Soveral I (2014) The immune system and aging: A review. Gynecol Endocrinol 30, 16-22. 
[61] Olczak T, Simpson W, Liu X, Genco CA (2005) Iron and heme utilization in Porphyromonas gingivalis. FEMS Microbiol Rev 29, 119-144.

[62] Olczak T, Siudeja K, Olczak M (2006) Purification and initial characterization of a novel Porphyromonas gingivalis HmuY protein expressed in Escherichia coli and insect cells. Protein Expr Purif 49, 299-306.

[63] Smalley JW, Olczak T (2017) Heme acquisition mechanisms of Porphyromonas gingivalis - strategies used in a polymicrobial community in a heme-limited host environment. Mol Oral Microbiol 32, 1-23.

[64] Anaya-Bergman C, Rosato A, Lewis JP (2015) Iron- and hemin-dependent gene expression of Porphyromonas gingivalis. Mol Oral Microbiol 30, 39-61.

[65] Gui MJ, Dashper SG, Slakeski N, Chen Y-Y, Reynolds EC (2016) Spheres of influence: Porphyromonas gingivalis outer membrane vesicles. Mol Oral Microbiol 31, 365-378.

[66] Dashper SG, Hendtlass A, Slakeski N, Jackson C, Cross KJ, Brownfield L, Hamilton R, Barr I, Reynolds EC (2000) Characterization of a novel outer membrane hemin-binding protein of Porphyromonas gingivalis. J Bacteriol 182, 64566462.

[67] Rangarajan M, Aduse-Opoku J, Paramonov NA, Hashim A, Curtis MA (2017) Hemin binding by Porphyromonas gingivalis strains is dependent on the presence of A-LPS. Mol Oral Microbiol 32, 365-374.

[68] Simpson W, Olczak T, Genco CA (2004) Lysine-specific gingipain $\mathrm{K}$ and heme/hemoglobin receptor HmuR are involved in heme utilization in Porphyromonas gingivalis. Acta Biochim Pol 51, 253-262.

[69] Goulet V, Britigan B, Nakayama K, Grenier D (2004) Cleavage of human transferrin by Porphyromonas gingivalis gingipains promotes growth and formation of hydroxyl radicals. Infect Immun 72, 4351-4356.

[70] Shizukuishi S, Tazaki K, Inoshita E, Kataoka K, Hanioka T, Amano A (1995) Effect of concentration of compounds containing iron on the growth of Porphyromonas gingivalis. FEMS Microbiol Lett 131, 313-317.

[71] Chiziane E, Telemann T, Krueger M, Adler J, Arnhold J, Alia A, Flemmig J (2018) Free heme and amyloid- $\beta$ : A fatal liaison in Alzheimer's disease. J Alzheimers Dis 61, 963-984.

[72] Flemmig J, Zámocký M, Alia A (2018) Amyloid $\beta$ and free heme: Bloody new insights into the pathogenesis of Alzheimer's disease. Neural Regen Res 13, 1170-1174.

[73] Lane DJR, Ayton S, Bush AI (2018) Iron and Alzheimer's disease: An update on emerging mechanisms. J Alzheimers Dis 64(s1), S379-S395.

[74] Singhrao SK, Olsen I (2018) Are Porphyromonas gingivalis outer membrane vesicles microbullets for sporadic Alzheimer's disease manifestation? J Alzheimers Dis Rep 2, 219-228.

[75] Pretorius L, Kell DB, Pretorius E (2018) Iron dysregulation and dormant microbes as causative agents for impaired blood rheology and pathological clotting in Alzheimer's type dementia. Front Neurosci 12, 851.

[76] Pretorius E, Bester J, Kell DB (2016) A bacterial component of Alzheimer's type dementia seen via a systemic biology approach that links iron dysregulation and inflammagen shedding to disease. J Alzheimers Dis 53, 1237-1256.

[77] Olsen I, Singhrao SK (2020) Low levels of salivary lactoferrin may affect oral dysbiosis and contribute to Alzheimer's disease: A hypothesis. Med Hypotheses 13, 110393.

[78] Lipinski B, Pretorius E (2013) The role of iron-induced fibrin in the pathogenesis of Alzheimer's disease and the protective role of magnesium. Front Hum Neurosci 7, 735.

[79] Budimir A (2011) Metal ions, Alzheimer's disease and chelation therapy. Acta Pharm 61, 1-14.

[80] Adlard PA, Bush AI (2012) Metal chaperones: A holistic approach to the treatment of Alzheimer's disease. Front Psychiatry 3, 15.

[81] Tahmasebinia F, Emadi S (2017) Effect of metal chelators on the aggregation of beta-amyloid peptides in the presence of copper and iron. Biometals 30, 285-293.

[82] Murayama H, Shin RW, Higuchi J, Shibuya S, Muramoto T, Kitamoto T (1999) Interaction of aluminium with PHFtau in Alzheimer's disease neurofibrillary degeneration evidenced by desferrioxamine-assisted chelating autoclave method. Am J Pathol 155, 877-885.

[83] Shin R-W, Kruck TPA, Murayama H, Kitamoto T (2003) A novel trivalent cation chelator feralex dissociates binding of aluminium and iron associated with hyperphosphorylated tau of Alzheimer's disease. Brain Res 961, 139-146.

[84] McLachlan DRC, Dalton AJ, Kruck TP, Bell MY, Smith WL, Kalow W, Andrews DF (1991) Intramuscular desferrioxamine in patients with Alzheimer's disease. Lancet 337, 1304-1308.

[85] Kell DB, Heyden EL, Pretorius E (2020) The biology of lactoferrin, an iron-binding protein that can help defend against viruses and bacteria. Front Immunol 11, 1221.

[86] Olsen I (2020) Possible link between Porphyromonas gingivalis and amyloidosis in the pathogenesis of Alzheimer's and Parkinson's disease. Int J Pathol Immunol 1, 1001.

[87] Liu J, Fan YG, Yang ZS, Wang ZY, Guo C (2018) Iron and Alzheimer's disease. From pathogenesis to therapeutic implications. Front Neurosci 12, 632.

[88] Wakabayashi H, Yamauchi K, Kobayashi T, Yaeshima T, Iwatsuki K, Yoshie H (2009) Inhibitory effects of lactoferrin on growth and biofilm formation of Porphyromonas gingivalis and Prevotella intermedia. Antimicrob Agents Chemother 53, 3308-3316.

[89] Dashper SG, Pan Y, Veith PD, Chen Y-Y, Toh ECY, Liu SW, Cross KJ, Reynolds EC (2012) Lactoferrin inhibits Porphyromonas gingivalis proteinases and has sustained biofilm inhibitory activity. Antimicrob Agents Chemother 56, 15481556. 